\title{
REPLIES
}

\section{What does incipient /ay/-raising look like? A response to Josef Fruehwald}

\author{
KELLY BERKSON \\ StUART Davis \\ Alyssa STRICKLER \\ Indiana University \\ Indiana University \\ Indiana University
}

In examining the history of /ay/-raising before voiceless consonants in Philadelphia, Josef Fruehwald (2016) concludes that either categorical phonological conditioning was present from the very onset of this phonetic change, or the period of purely phonetic conditioning was too brief to be identified. This is based on the observation that raising is phonological in the Philadelphia data: it occurs before voiced flaps that are underlyingly voiceless (as in writing), but not before underlyingly voiced flaps (as in riding). In this response, we provide the first acoustic documentation of an English variety that shows an incipient phase of /ay/-raising where the conditioning environment is purely phonetic.*

Keywords: Canadian raising, phonologization, incipient sound change, flapping, metrical foot

CANADIAN RAISING - wherein the diphthongs /ay/ and /aw/ surface as / $\mathrm{yy} /$ and $/ \Lambda \mathrm{w} /$ before voiceless consonants - has been a topic of linguistic interest since at least 1942, when Martin Joos published 'A phonological dilemma in Canadian English' in the eighteenth volume of Language (Joos 1942). In the intervening years many others have written about raising - in Canada and elsewhere, and in this journal and elsewhere - in part because of the following facts. Raising occurs before a voiceless consonant, so words with voiceless codas like write and knife are produced with the raised [ $\Lambda \mathrm{y}$, while those with voiced codas like ride and knives have the lower variant, [ay]. It also occurs before a flapped $/ t /$, however, such that writing surfaces with the higher variant of the diphthong, [ıиугіn]. This can be considered phonological raising in that it is triggered before a $t$-flap, which is voiced on the surface, because the $/ \mathrm{t} /$ is underlyingly voiceless. In other words, it is not the phonetic realization of the trigger that is relevant but rather the underlying phonological specification. These facts have served as fodder for lively debate about phonological opacity (among others: Halle 1962, Chambers 1973, Mielke et al. 2003, Idsardi 2006).

Most recently, Josef Fruehwald's 'The early influence of phonology on a phonetic change' appeared last year in Language 92.2 (Fruehwald 2016). Fruehwald presents careful analysis of raising in Philadelphia English using longitudinal data from the Philadelphia Neighborhood Corpus (Labov \& Rosenfelder 2011), which includes speech from people born as early as 1889 and as late as 1998 . He finds that in the Philadelphia raising data all of the /ay/ diphthongs before underlyingly voiceless consonants pattern together, regardless of the surface voicing specification of the trigger. That is to say, when raising is present before surface-voiceless sounds as in write, it is also present before underlyingly voiceless (but surface-voiced) sounds such as the $t$-flap in writing. About these data, Fruehwald notes:

There is, in fact, no detectable period where the pattern of /ay/-raising aligned with what would be predicted on purely phonetic grounds. The conclusion I draw is that the period of purely phonetic condi-

* We want to thank Ricardo Bermúdez-Otero, who shared valuable insights - as well as a handout of one of his talks - with us. We are grateful for his input and for the input we received from audience members at NWAV 45 in Vancouver, where a preliminary poster version of this paper was presented, and at a colloquium talk at the University of New Mexico in February 2017. Additional thanks go to the editors of this journal, who gave important feedback on an earlier version of this paper, and to Adam Albright, who shared insightful comments on American varieties of Canadian raising. 
tioning either was too brief to be identified or was nonexistent. If the situation is the former, then that means there is a greater challenge than perhaps has been appreciated in identifying phonologization in vivo. (p. 404)

We concur with his observation that the period of phonetic raising is brief and that raising phonologizes quickly, making it easy to miss. Specifically, the incipient phase of Canadian raising has yet to be acoustically documented. The 'in vivo' or incipient stage would be where the raising only occurs before surface voiceless consonants like the [t] in write, but not in writing. However, we have identified purely phonetic raising in Fort Wayne, Indiana. In studies currently underway, we find that college-aged talkers from Fort Wayne who exhibit phonetic raising fall into roughly two groups: for some talkers, raising occurs before many phonetically voiceless triggers; for others, it is in an even more incipient stage and occurs in extremely limited environments.

In this paper we share data from two talkers who exemplify these two patterns. We suggest that part of the reason purely phonetic raising has been so elusive is not only because it disappears quickly but also because it appears first in environments that we do not typically consider - indeed, in environments where raising seems to disappear after phonologization. With this in mind we propose a phonologization path that may obtain. Our hope is to encourage collection of similar data in other dialect areas in order to probe the validity of our proposal.

That purely phonetic raising is elusive - if in fact it exists - is not a new observation. Joos himself noted the existence of two dialects in Ontario English in 1942. In what he called group A, raising had phonologized and the raised variant of the diphthong occurred before sounds that were surface-voiceless and before flaps that were underlyingly voiceless. He provides the example of typewriter, noting that speakers in what he

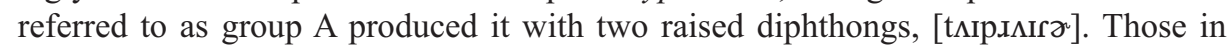
group B, meanwhile, showed phonetic raising: the diphthong raised before the surfacevoiceless [p] but failed to raise before the surface-voiced flap- $t$, so that for them typewriter was produced [tıIрлаггґ]. By 1973, however, this dialect was no longer in evidence in Ontario; Jack Chambers reported that 'in the three intervening decades Dialect B has disappeared and Dialect A is ubiquitous throughout heartland Canada' (Chambers 1973:122). Putting quite a fine point on it indeed, Jonathan Kaye makes the observation that 'all that remains of Dialect B is a single datum: Joos's transcription of the word typewriter' (Kaye 1990:262). This aligns with Fruehwald's observation about raising in Philadelphia: the period of phonetic raising reported by Joos to exist in Ontario in 1942 was brief enough that it disappeared too quickly to be documented more thoroughly. We cannot note exactly how quickly it disappeared, but the end result is that we have only limited evidence of a group of purely phonetic raisers.

If the so-called dialect B pattern-Fruehwald's 'period of purely phonetic conditioning' - is fleeting, capturing it would require one to be in the right place at the right time. Looking at the right test items, and capturing data that could be subjected to instrumental analysis, would also be beneficial. We think we have done this, somewhat accidentally. Casual observation that raising had begun to occur in Indiana-only in the last decade, and in the area of Fort Wayne in northeastern Indiana - suggested to us that this would be a good opportunity to document incipient raising, and so we began recording speakers. In general, what we have found is that college-aged talkers from Fort Wayne show various degrees of raising, while their parents and grandparents (even those living in the same household) may not have it. Data collection is ongoing, and subjects include talkers of both sexes and all ages. Our current focus is on Fort Wayne, but we are recording talkers from all over Indiana and will use those data in future work. 
The data described here are from lab speech. Participants produced three repetitions of a pseudo-randomized word list containing thirty-eight /ay/ targets (lice/lies, write/ ride, writing/riding, and so forth) and fillers. The analysis presented here focuses on twenty-six of the target items, a complete list of which appears in the appendix. Diphthongs in target stimuli were annotated in Praat (Boersma \& Weenink 2016), and duration and time-normalized F1 measures were taken with FormantPro (Xu 2007-2015) and hand-checked for validation. Following Labov and colleagues (2006) and Rankinen (2014), a difference of more than $60 \mathrm{~Hz}$ in mean F1 is considered a general diagnostic for raising.

To date, we have analyzed data for twenty-seven speakers (sixteen female, eleven male), who range in age from nineteen to seventy-eight years old. The subjects exhibit four basic patterns of behavior with regard to raising, which we call INCIPIENT PATTERNS $0,1,2$, and 3 . Two of these-patterns 1 and 2-are phonetic in nature. The distribution of speakers across these patterns is shown in Table 1. Briefly, in pattern 0 there is no raising, while in pattern 3 raising has phonologized. Pattern 3 speakers produce the raised variant of the diphthong both before surface-voiceless codas (as in write) and before flaps that are underlyingly voiceless (as in writing). Patterns 1 and 2 fall between these two extremes and are the patterns of key interest here, for they are the ones wherein phonetic raising is evident. As seen in Table 1, roughly two thirds of our talkers exhibit patterns 1 and 2. Each is discussed more thoroughly below. (We leave for future research an analysis of the interesting gender difference reflected in Table 1.)

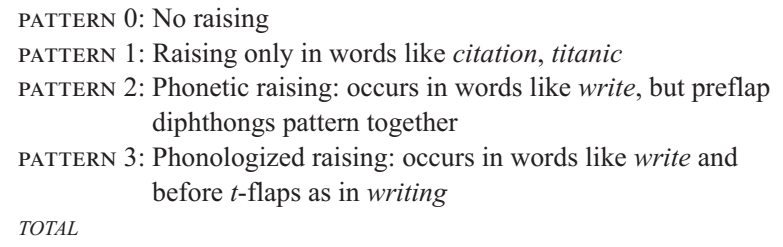

TABLE 1. Distribution of subjects across the four patterns observed in Fort Wayne speech.

$\begin{array}{ccc}\text { FEMALE } & \text { MALE } & \text { TOTAL } \\ 1 & 3 & 4 \\ 3 & 5 & 8 \\ 7 & 2 & 9 \\ 5 & 1 & 6 \\ 16 & 11 & 27\end{array}$

Pattern 2 is discussed first, because we believe it represents the phonetically conditioned raising pattern that has been so elusive. Pattern 1, which we suggest is a precursor to pattern 2, contains raising only in the very shortest of diphthongs. Speakers who exhibit pattern 1 might go unnoticed as raisers unless test items include the diphthong of interest in a particular morphological and prosodic environment - specifically, in syllables immediately preceding a primary stress in words like titanic and citation. This pattern is intriguing because these very items are reported not to undergo raising in Canadian English (Chambers 1973, 1989), a point we return to shortly.

To illustrate patterns 1 and 2, we use representative data from two young female talkers who were born and raised in Fort Wayne and who moved to Bloomington, Indiana, to attend Indiana University at approximately eighteen years of age. Speaker P (for 'phonetic raiser') is among the seven female talkers (7/16, or 44\%) who exhibit incipient pattern 2. Speaker TI (for 'truly incipient raiser') is among the three female talkers (3/16, or $19 \%)$ who exhibit incipient pattern 1 .

As noted, pattern 2 is something akin to the group B/dialect B pattern of Joos (1942). The raised diphthong appears before surface-voiceless sounds. Speaker P is a twentyyear-old female with incipient pattern 2 raising — in other words, she has raising before the voiceless consonant in a minimal pair like write and ride. This is illustrated in Fig- 
ure 1, which - like all of the F1 plots that follow — depicts the time course of F1 in raw $\mathrm{Hz}$ plotted on an inverted y-axis, so that a raised vowel appears higher on the graph. Data are time-normalized, with 10\% representing the mean F1 value of the first ten percent of each item and so forth. Recall that speakers produced three repetitions of the word list: shown in Fig. 1 are the F1 tracks for the diphthong in each of speaker P's three productions of write and of ride. While there is some variation across productions, the raising in write is consistent. Differences in F1 values at the 30\% mark-one third of the way into the vowel, still firmly within the vowel nucleus but somewhat removed from coarticulatory effects found at vowel onset - exceed the $>60 \mathrm{~Hz}$ metric (for ride, $M=910 \mathrm{~Hz}, S D=43$; for write, $M=716 \mathrm{~Hz}, S D=47$ ).

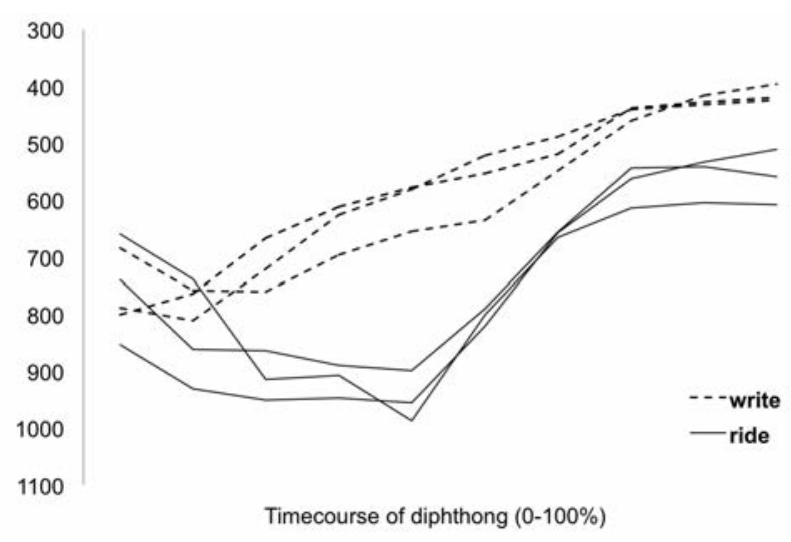

FIGURE 1. Time course of F1 in /ay/ for speaker P's productions of write and ride. There is variation across repetitions, but consistent raising occurs in write.

The observed pattern is present in monosyllables in general for speaker P. This is illustrated in Figure 2a, which shows mean F1 tracks for the diphthong in monosyllables with voiceless codas (bike, cite, fight, knife, lice, life, pike, psych, rice, write), those with voiced obstruent codas (lies, ride, rise), and those that are open syllables (buy, pie, tie). Again, $\mathrm{F} 1$ (in $\mathrm{Hz}$ ) is plotted on an inverted y-axis, so a raised vowel is higher, and the $\mathrm{x}$-axis represents the time-normalized time course of the vowel. Mean F1 values at the $30 \%$ mark are $873 \mathrm{~Hz}(S D=131)$ before voiceless codas, $1017 \mathrm{~Hz}(S D=122)$ before voiced obstruent codas, and $1009 \mathrm{~Hz}(S D=131)$ in open syllables. The inset bar chart (here and in the following panels) represents mean duration (in milliseconds). The diphthong is shorter before voiceless than before voiced codas and is longest in open syllables.

What of the phonological raising environment, however? As shown in Figure 2b, raising does not extend to the preflap environment for speaker P. Note that the data shown here are for individual words - the F1 track for write is averaged across speaker P's three repetitions of write, which were shown separately in Fig. 1. What we see in Fig. $2 b$ is that speaker P's pattern is phonetic in that the raised variant of /ay/ is produced only before surface voiceless sounds. Preflap diphthongs pattern together, regardless of the underlying voicing specification of the flap. Though they are slightly raised in comparison to ride, they more closely approximate the low variant found therein than they do the raised variant found in write. These points are illustrated in Fig. $2 \mathrm{~b}$ using the individual words that comprise the only minimal set we have in our data (write, writing, riding, ride), because phonology is, after all, about contrast. While the other preflap items contained in our data pattern similarly, we in fact failed to include 
other $d$-flap items in our original word list that are not monomorphemic (the other $d$-flap items being monomorphemic spider and Snyder). In future work we plan to collect additional minimal sets such as bite/biting/biding/bide. With regard to mean durations, meanwhile, those in Fig. $2 b$ align with expectations. The diphthong is shorter in write than in ride, and is shorter still before both the $t$-flap and the $d$-flap.

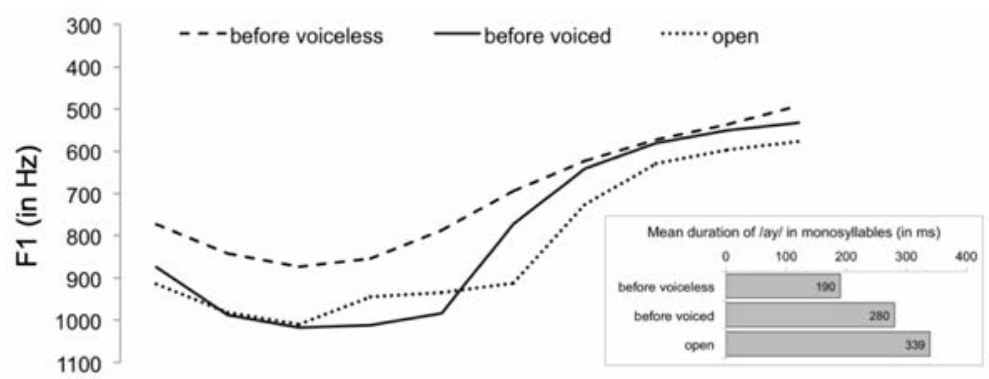

a. Time-normalized F1 tracks for /ay/ in monosyllables. On inverted y-axis, raised vowels are higher. Raising occurs before voiceless codas: a third of the way into the vowel, differences exceed the $>60 \mathrm{~Hz}$ metric. Mean duration (in $\mathrm{ms}$ ), as expected, is greatest in open syllables. Voiceless codas are associated with shorter vowels.

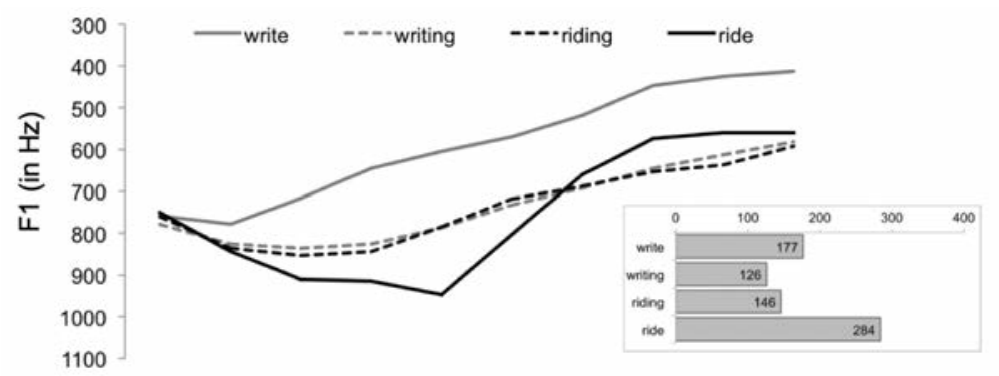

b. Though speaker P raises in monosyllables, evident here in both the nucleus and offglide of write, raising does not extend to preflap environments. Preflap diphthongs more closely approximate the lower variant of the diphthong, and-crucially - pattern together.

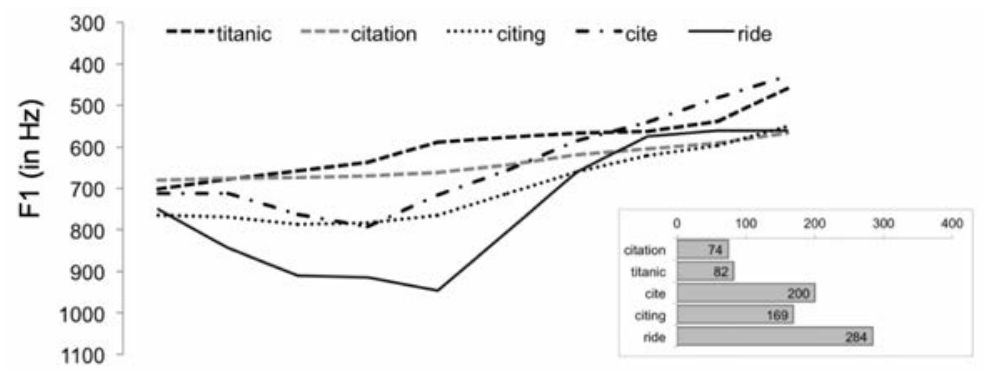

c. Canadian English is not characterized by raising in items like citation/titanic, where the diphthong immediately precedes a primary stressed syllable (Chambers 1973:125). Speaker P shows raising in precisely this prosodic environment: the diphthongs here are very short ('prefortis clipping', à la Wells 1990, Bermúdez-Otero 2014) and are the most raised.

FIGURE 2. Incipient pattern 2 (phonetic raising). Time course of F1 and /ay/ duration for speaker P, who shows phonetically conditioned raising.

Presented in Figure 2c are items related to the observations made by Chambers (1973, 1989 ) and others that raising unexpectedly fails to occur in certain items in Canadian En- 
glish. Chambers's 1989 analysis (in American Speech), roughly speaking, is that raising does not occur before a syllable with primary stress. That is, raising occurs within a metrical foot, and Chambers specifically notes citation and titanic as occurring with unraised diphthongs (1989:78). Not so for speaker P, however. The diphthongs in citation and titanic are very short, showing extreme 'prefortis clipping' à la Wells (1990) and Bermúdez-Otero (2014), and show more extreme raising even than cite. Furthermore, it looks like there is a paradigm effect that is already incipient in these data: although writing and riding patterned more closely with ride in Fig. 1b, citing (mean F1 at the $30 \%$ mark $=787 \mathrm{~Hz}, S D=41)$ patterns more like cite $(M=762 \mathrm{~Hz}, S D=100)$ than like ride $(M=910 \mathrm{~Hz}, S D=43)$ in Fig. 1c. That is to say, for speaker P the diphthong before the $t$-flap in citing is raised more than the diphthong before the $t$-flap in writing. We suspect that this is relevant to the question of how raising phonologizes, with paradigm effects influencing extension to preflap environments.

In Figure 3 we see data for speaker TI. Like speaker P, speaker TI is twenty years old. In parallel with Fig. 2, data for monosyllables are presented in Fig. 3a, for flap environments in Fig. 3b, and for the prosodic conditions of interest in Fig. 3c. As before, F1 (in $\mathrm{Hz}$ ) is plotted on an inverted $\mathrm{y}$-axis so raised vowels are higher, and the $\mathrm{x}$-axis represents the time-normalized time course of the diphthong. Inset bar charts in each panel represent mean duration of various items (in ms). In Figure $3 \mathrm{a}$, we see that no raising is present in monosyllables with a voiceless coda (bike, cite, fight, knife, lice, life, pike, psych, rice, write) for speaker TI. Mean F1 values at the 30\% mark are $903 \mathrm{~Hz}(S D=$ 63) before voiceless codas, $915 \mathrm{~Hz}(S D=39)$ before voiced obstruent codas (lies, ride, rise), and $922 \mathrm{~Hz}(S D=25)$ in open syllables (buy, pie, tie). Prevoiceless diphthongs are more variable, a point we return to below. They are also shorter than diphthongs in open syllables or before voiced codas, as was true for speaker P, but this does not coincide with the raised variant of /ay/.

Of note in Figure $3 \mathrm{~b}$ is that while neither the monosyllable write nor the preflap environment of writing/riding show raising in the diphthong nucleus, there is offglide peripheralization in the monosyllable write. This is of particular interest because it is the phonetic precursor to raising proposed by Moreton (2004) and Moreton and Thomas (2007). One additional point of interest in Fig. $3 b$ is that once again the preflap diphthongs pattern together, regardless of underlying phonological specification.

In Figure 3c, we see that the very shortest diphthongs - those in titanic and citation, where they occur immediately before a syllable with primary stress - are raised. Speaker TI showed no raising in monosyllables, although the offglide peripheralization in write in Fig. $3 \mathrm{~b}$ may suggest a latent pattern. By considering the items in Fig. 3c, however, we find that speaker TI does in fact have raising - albeit in a very specific environment. Again, paradigm effects seem to be incipient: not only does the offglide of cite show peripheralization, in line with write, but in fact we also see slight raising in the nuclei of cite (at the $30 \%$ mark, $M=824 \mathrm{~Hz}, S D=15)$ and citing $(M=813 \mathrm{~Hz}$, $S D=17)$. This contrasts with the nuclei of the diphthongs in write $(M=904 \mathrm{~Hz}, S D=$ $24)$ and in writing $(M=908 \mathrm{~Hz}, S D=4)$, which were unraised when compared to ride $(M=936 \mathrm{~Hz}, S D=7)$.

To recap, then, speaker $\mathrm{P}$ shows a phonetic raising pattern: the raised variant of /ay/ is produced before surface voiceless sounds in items like write, citation, and titanic. Underlyingly voiceless sounds that are phonetically voiced, such as the $t$-flap in writing, do not serve as a trigger for raising. Rather, /ay/ before flaps patterns similarly, regardless of the underlying phonological specification of the flap. This pattern is akin to Joos's dialect B, with the purely phonetic conditioning that Fruehwald posited might 


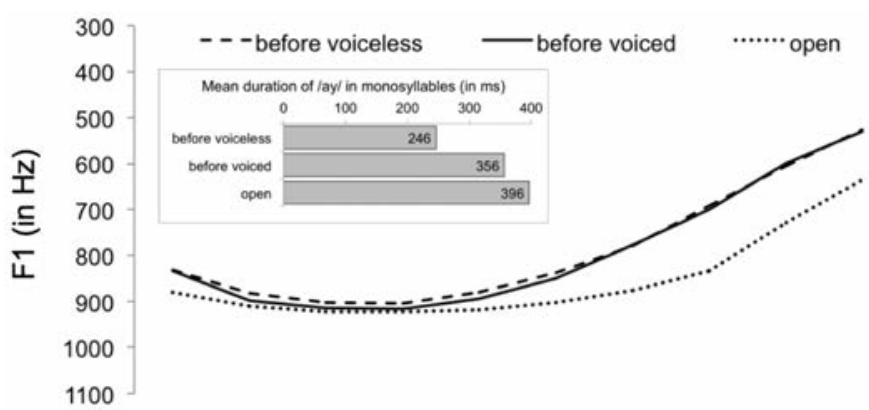

a. No raising in monosyllables for speaker TI. Vowels are shortest before voiceless codas.

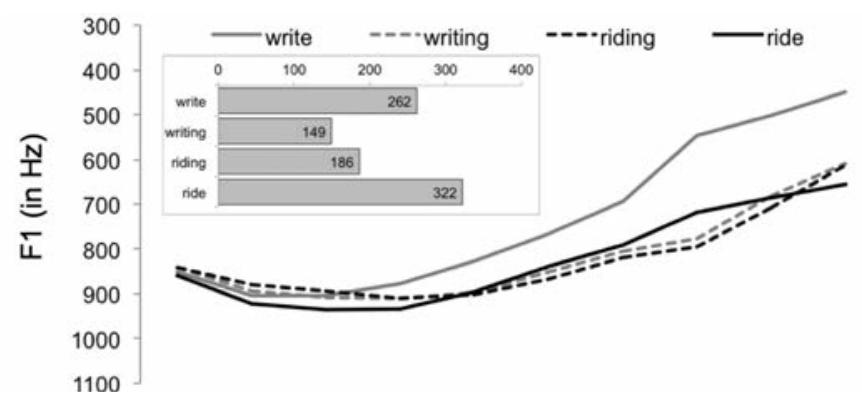

b. Raising does not occur in the nuclei of write or in the preflap environment, but offglide peripheralization occurs in monosyllabic write. This is the phonetic precursor to raising proposed by Moreton (2004).

Preflap diphthongs pattern together, regardless of underlying phonological specification.

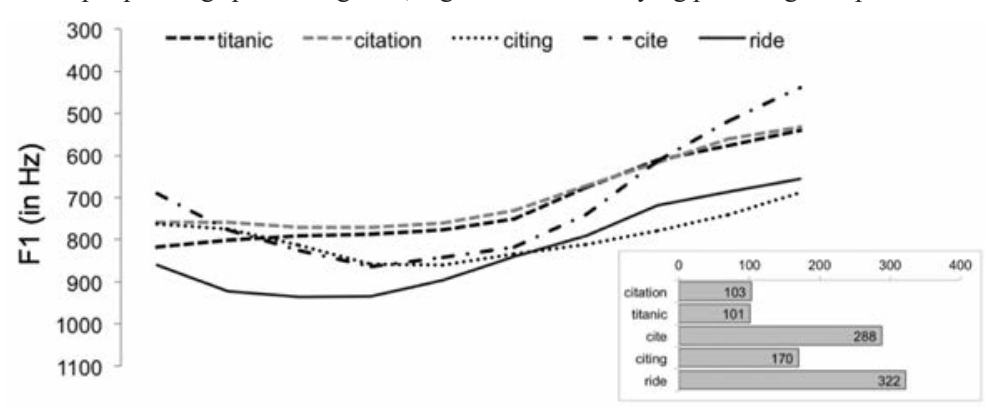

c. In the very shortest diphthongs - those immediately preceding a syllable with primary stress in titanic and citation - speaker TI in fact shows raising. The other hint that raising may be incipient for this speaker came in (b), which showed offglide peripheralization in write. Raising may extend, however: nuclei in cite/citing are higher than those in write/writing, suggesting possible extension.

FIGURE 3. Incipient pattern 1 (truly incipient raising). F1 and duration of /ay/ for speaker TI. Only the shortest vowels (those before a primary stress) raise.

exist so briefly that it would be difficult to capture. Speaker TI, meanwhile, appears to show an even earlier stage: for her, raising occurs only in the very shortest of diphthongs - those preceding primary stress in items like citation.

Recall, though, that as shown in Fig. 3a, speaker TI showed signs of variation in prevoiceless diphthongs, which had a mean value at the 30\% mark of $903 \mathrm{~Hz}$ but a relatively larger standard devation $(S D=63)$ than the other categories. This may indicate that raising is already beginning to spread-indeed, among speaker TI's prevoiceless monosyllables it is only cite (a member of the cite/citing/citation paradigm) and psych (a member of the psych/psychotic/psychology paradigm, also recorded but not presented 
here) that are produced with somewhat raised diphthongs. Compare values at the $30 \%$ mark for fight $(M=914 \mathrm{~Hz}, S D=14)$ or life $(M=917 \mathrm{~Hz}, S D=29)$, which are not members of such a paradigm, with values for cite $(M=824 \mathrm{~Hz}, S D=15)$ and psych $(M=773 \mathrm{~Hz}, S D=16)$. This is illustrated in Figure 4, which shows the F1 tracks for /ay/ in individual monosyllabic tokens. Dotted lines represent the diphthong before voiceless codas, and solid lines the diphthong before voiced codas. In Figure 4a, which presents speaker TI's data, the two prevoiceless diphthongs that are beginning to show raisingthat rise above the others on the graph, in other words - are cite and psych. In comparison, speaker P's data appear in Figure 4b: here, the trend of raising before a voiceless coda is consistent.

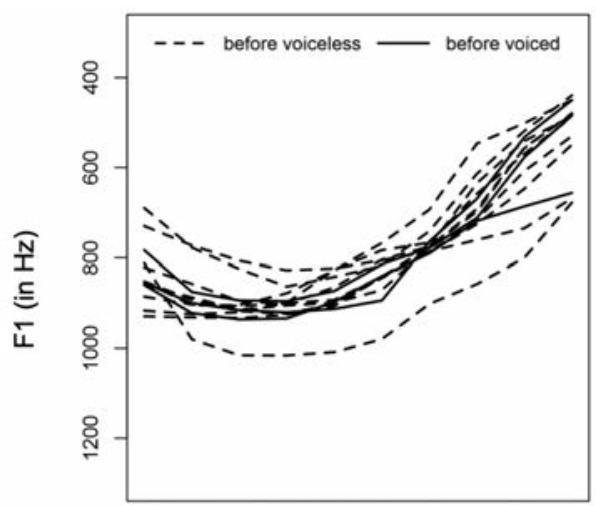

a. Speaker TI, the truly incipient raiser: F1 tracks for /ay/ in individual monosyllabic tokens (see list in the appendix). Dashed lines represent the diphthong before voiceless codas, and solid lines the diphthong before voiced codas. Individual tokens vary, and the raising effect is not yet consistent. However, two items

(specifically: cite and $p s y c h$ ) are beginning to raise, likely due to influence from citation and psychotic/psychology.

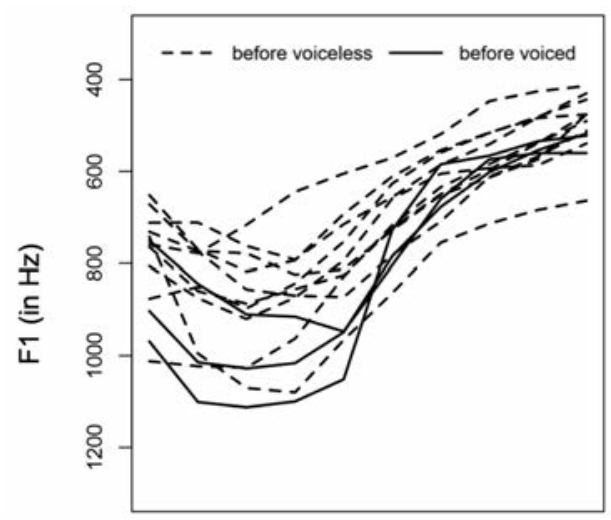

b. Speaker P, the phonetic raiser: F1 tracks for /ay/ in individual monosyllabic tokens. Dashed lines represent the diphthong before voiceless codas, and solid lines the diphthong before voiced codas. Individual tokens vary, but there is a strong trend of raising before a voiceless coda.

FIGURE 4. Time course of F1 in /ay/ in monosyllables before voiceless and voiced codas.

This further suggests that paradigm effects may play a role in the spread of raising beyond incipient pattern 1, but a matter for future research is the question of how the effects play out. By this we mean that many factors could influence the spread of raising, including such things as the number of lexemes within a class, the coarticulatory 
influence of surrounding consonants, word frequency, and so forth. What also remains unanswered at present is the question of how one goes from the phonetic to the phonological pattern: we have identified at least two phonetic patterns of raising, but whether there is a linear progression from one pattern to the next or whether some speakers jump from pattern 1 directly to pattern 3 , for instance, remains unknown.

We hypothesize that incipient patterns 1 and 2 may be two of the earliest stages in the advent and phonologization of raising. The prosodic environment that is most conducive to phonetic raising as reflected by incipient pattern 1 - where raising happens only before a syllable with primary stress in items like citation - is when the diphthong is durationally very short, but raising is difficult to detect here. In such environments, which are uncommon in spoken contexts and often are not elicited, raising may not be auditorily salient and its presence may go unnoticed without instrumental analysis. By the time raising is detectable, it has phonologized.

How might this phonologization happen? One possibility is that because of paradigm effects, which are already incipient in the data we have (wherein cite and citing pattern with citation), raising spreads. It begins to occur before $t$-flaps and is then phonologized. The metrical condition, wherein raising happens when the trigger is foot-internal (i.e. in cite and citing, but not in citation), perhaps only arises with subsequent generations. Once phonological raising is established in a community and children hear the patterned allophony in their input, they may impose some sort of prosodic conditioning: namely, they impose a foot-internal environment on raising so that both the target diphthong and the following voiceless phoneme must be in the same foot. The varieties of Canadian raising described by Chambers (1973, 1989), Vance (1987), and DaileyO'Cain (1997) all have a metrical condition on raising. The suggestion that the footinternal prosodic conditioning only arises with a subsequent (nonincipient) generation of Canadian raisers is consistent with the observation from the L1 phonological literature on English that children often impose metrical constraints on the distribution of allophony as part of the acquisition process (e.g. Inkelas \& Rose 2007, Davis 2010, Rose \& Inkelas 2011, among others). Given that a metrical distribution is witnessed for the early target-like acquisition of English aspiration (Inkelas \& Rose 2007:712, Redford \& Gildersleeve-Neumann 2007), it is not surprising that children may impose a metrical analysis more generally on allophonic distribution as part of the acquisition process. As a consequence, we suggest that the metrical environment found with /ay/-raising is not part of the incipient stage, which is purely phonetic, as illustrated by the data from speakers 1 and 2 . They both raise before the voiceless $\left[\mathrm{t}^{\mathrm{h}}\right]$ in citátion and titánic even though the $\left[\mathrm{t}^{\mathrm{h}}\right]$ is at the beginning of a metrical foot. We do not expect the incipient generation of Fort Wayne Canadian raisers to undo the raising in these words. However, a subsequent generation of Fort Wayners who grow up hearing /ay/-raising in their home environment may impose a prosodic analysis on its allophonic distribution, thus undoing raising in the incipient environments of words like citation and titanic in which raising initially occurred.

To conclude, we have proposed that the stage in which Canadian raising is subject to purely phonetic conditioning is, as stated explicitly by Fruehwald (2016) and hinted at by others, exceedingly brief. By virtue of being in the right place at the right time and eliciting the right items, however, we have identified such raising - similar to Joos's group B - in the speech of college-aged talkers from Fort Wayne, Indiana. Data from two speakers were used to illustrate the two phonetic raising patterns we are observing in a study that is ongoing: in the first, incipient pattern 1, raising occurs in limited prosodic environments - notably, not within a metrical foot but rather immediately preceding a stressed syllable, in vowels of extremely short duration. Incipient pattern 2 
shows phonetic raising, with raised variants of /ay/ surfacing before phonetically voiceless triggers. These speakers are part of a community in the midst of an incipient sound change, and two additional patterns are found as well: incipient pattern 0 , exhibited by $15 \%$ of the twenty-seven talkers analyzed thus far, is characterized by no raising at all. Incipient pattern 3 , in which raising has phonologized, is exhibited by $22 \%$ of the talkers. Almost two thirds of the speakers reported on here exhibit either pattern $1(30 \%$ of the talkers) or pattern 2 (33\%). We expect that incipient pattern 1 exists, or has existed, in other dialects, but that it is difficult to detect without instrumental analysis. Furthermore, the raising is in an environment that is often not elicited. We also expect that incipient pattern 2 exists, or has existed, in other dialects as well, but that phonologization happens quickly - maybe even within the incipient generation. Our findings support the theory of sound change put forward by Janda and Joseph (2003) and briefly discussed by Fruehwald (2016:404), in which they propose that phonetic factors guide sound change only for a brief period before phonologization takes place. We continue to collect data in Fort Wayne from both male and female talkers of varying ages and backgrounds. Ideally we will track the same incipient raisers over time, thereby gaining additional insight into their evolving systems.

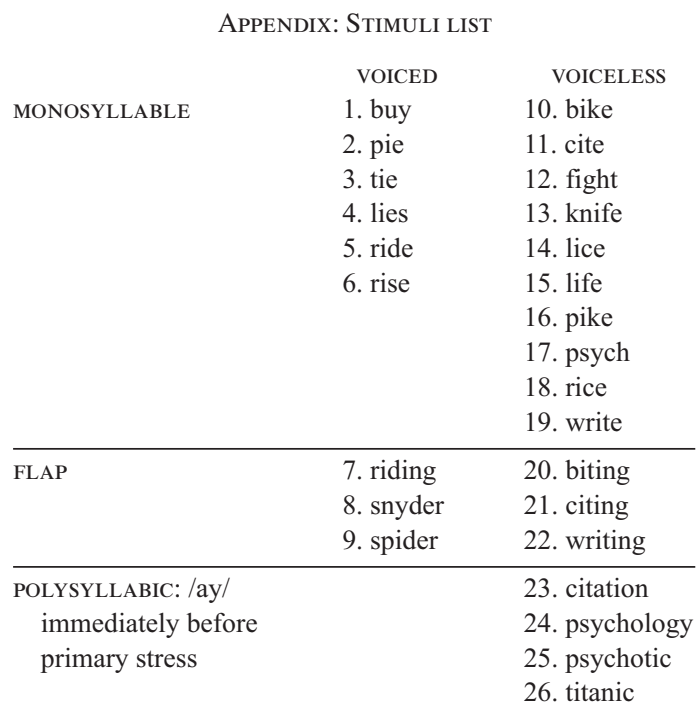

\section{REFERENCES}

Bermúdez-Otero, Ricardo. 2014. The diachronic rise and synchronic representation of phonological opacity: A case study. Handout of a talk presented at RALFe, Paris, October 9-10, 2014.

Boersma, Paul, and David Weenink. 2016. Praat: Doing phonetics by computer. Version 6.0.22. Online: http://www.praat.org/.

Chambers, JACK K. 1973. Canadian raising. Canadian Journal of Linguistics/Revue canadienne de linguistique 18(2).113-35. DOI: 10.1017/S0008413100007350.

Chambers, JACK K. 1989. Canadian raising: Blocking, fronting, etc. American Speech 64(1). 75-88. DOI: $10.2307 / 455114$.

Dailey-O'CAIN, JENnIFER. 1997. Canadian raising in a midwestern US city. Language Variation and Change 9(1).107-20. DOI: 10.1017/S0954394500001812.

Davis, Stuart. 2010. Distributional evidence for the foot from the L1 acquisition of American English. Phonological Studies 13.39-50.

Fruenwald, Josef. 2016. The early influence of phonology on a phonetic change. Language 92(2).376-410. DOI: 10.1353/lan.2016.0041. 
Halle, MorRIs. 1962. Phonology in generative grammar. Word 18(1-3).54-72. DOI: 10 $.1080 / 00437956.1962 .11659765$.

IDSARDI, WiLliam. 2006. Canadian raising, opacity, and rephonemicization. The Canadian Journal of Linguistics/La revue canadienne de linguistique 51(2).119-26. DOI: 10.1353 /cj1.2008.0007.

Inkelas, Sharon, and Yvan Rose. 2007. Positional neutralization: A case study from child language. Language 73(4).707-36. DOI: 10.1353/lan.2008.0000.

JANDA, RICHARD, and BRIAN JOSEPH. 2003. Reconsidering the canons of sound change: Towards a 'big bang' theory. Historical linguistics 2001: Selected papers from the 15th International Conference on Historical Linguistics, Melbourne, ed. by Barry Blake and Kate Burridge, 205-19. Amsterdam: John Benjamins.

Joos, Martin. 1942. A phonological dilemma in Canadian English. Language 18(2).14144. DOI: $10.2307 / 408979$.

Kaye, Jonathan. 1990. What ever happened to dialect B? Grammar in progress: GLOW essays for Henk van Riemsdijk, ed. by Joan Mascaró and Marina Nespor, 259-63. Dordrecht: Foris.

Labov, William; Sherry Ash; and Charles Boberg. 2006. The atlas of North American English: Phonetics, phonology and sound change. New York: Mouton de Gruyter.

Labov, William, and Ingrid Rosenfelder. 2011. The Philadelphia Neighborhood Corpus. Philadelphia: University of Pennsylvania. Online: http://fave.ling.upenn.edu/pnc .html.

Mielke, Jeff; Mike Armstrong; and Elizabeth Hume. 2003. Looking through opacity. Theoretical Linguistics 29(1-2).123-39. DOI: 10.1515/thli.29.1-2.123.

Moreton, Elliott. 2004. Realization of the English postvocalic [voice] contrast in $F_{1}$ and $F_{2}$. Journal of Phonetics 32(1).1-33. DOI: 10.1016/S0095-4470(03)00004-4.

Moreton, Elliott, and EriK Thomas. 2007. Origins of Canadian raising in voiceless coda effects: A case study in phonologization. Papers in laboratory phonology 9, ed. by Jennifer Cole and José Ignacio Hualde, 37-64. Cambridge: Cambridge University Press.

Rankinen, Wil A. 2014. The sociophonetic and acoustic vowel dynamics of Michigan's Upper Peninsula English. Bloomington: Indiana University dissertation.

Redford, Melissa A., and Christina E. Gildersleeve-Neumann. 2007. The acquisition of two phonetic cues to word boundaries. Journal of Child Language 34(4).815-43. DOI: $10.1017 / \mathrm{S} 0305000907008203$.

Rose, Yvan, and Sharon Inkelas. 2011. The interpretation of phonological patterns in first language acquisition. The Blackwell companion to phonology, vol. 4, ed. by Marc van Oostendorp, Colin Ewen, Elizabeth Hume, and Keren Rice, 2414-38. Oxford: Wiley-Blackwell.

Vance, Timothy. 1987. 'Canadian raising' in some dialects of the northern United States. American Speech 62(3).195-210. DOI: 10.2307/454805.

WeLLS, John C. 1990. Syllabification and allophony. Studies in the pronunciation of English: A commemorative volume in honour of A.C. Gimson, ed. by Susan Ramsaran, 76-86. London: Routledge.

Xu, YI. 2007-2015. FormantPro.praat. Online: http://www.phon.ucl.ac.uk/home/yi/Formant Pro/.

Linguistics Department

Indiana University, Bloomington

1020 E. Kirkwood Ave.

Ballantine Hall Rm 844

Bloomington, IN 47405

[kberkson@indiana.edu] (Berkson)

[davis@indiana.edu] (Davis)

[arstrick@umail.iu.edu] (Strickler)
[Received 16 January 2017; revision invited 22 January 2017; revision received 7 March 2017; accepted 12 March 2017] 